\title{
BRAF Protein Variant
}

National Cancer Institute

\section{Source}

National Cancer Institute. BRAF Protein Variant. NCI Thesaurus. Code C98307.

A variation in the amino acid sequence for the serine/threonine-protein kinase B-raf protein. 